Article

\title{
Collaboration Mechanisms of Taiwan Nonprofit Organizations in Disaster Relief Efforts: Drawing Lessons from the Wenchuan Earthquake and Typhoon Morakot
}

\author{
Wei-Ning $\mathrm{Wu}^{1,2}$ and Ssu-Ming Chang ${ }^{3, *}$ \\ 1 Institute of Public Affairs Management, National Sun Yat-sen University, Gushan District, Kaohsiung 80424, \\ Taiwan; weiningwu@mail.nsysu.edu.tw \\ 2 Visiting Scholar of the Institute of East Asian Studies, University of California at Berkeley, \\ Berkeley, CA 94720, USA \\ 3 Department of Public Administration and Policy, National Taipei University, 151, University Rd., \\ San Shia District, New Taipei 23741, Taiwan \\ * Correspondence: chang107@mail.ntpu.edu.tw; Tel.: +1-886-2-8671-1006
}

Received: 3 September 2018; Accepted: 13 November 2018; Published: 21 November 2018

check for check for
updates

\begin{abstract}
Participation of nonprofit organizations (NPOs) is important in emergency management because NPOs often work in conjunction with governments to offer assistance and resources in the emergency management process. NPO participation in disaster relief efforts is a valuable experience for public officials and practitioners, but research investigating NPOs' experiences in disaster relief efforts is limited. This study examines Taiwan's NPO collaboration mechanisms during disaster relief efforts and specifically examines the lessons drawn from two major catastrophes by focusing on the opinions of NPO managers in the 88 Flooding Service Alliance who joined the disaster relief operation for the 2008 Wenchuan Earthquake in China and 2009 Typhoon Morakot in Taiwan. The vital strategies and factors that contributed to successful NPO collaborations in disaster relief operations were determined through a survey on NPOs' strategies for resource sharing and service integration and semi-structured interviews with 19 NPO managers. The findings indicate that NPO engagement in disaster services was crucial for the relief efforts of the two disaster events, and that long-term disaster service alliances are effective mechanisms for emergency collaboration in relief work.
\end{abstract}

Keywords: nonprofit organizations; collaboration; emergency management; Taiwan

\section{Introduction}

Over the past few decades, the frequency and scale of natural disasters have increased and caused challenges in collaboration for disaster relief operations at national and local levels. Scholars and professional organizations have endorsed the importance of collaborative emergency management, because a single bureaucracy cannot respond in a timely and effective manner to disaster events $[1,2]$. Emergency management is affected by various factors, including participants, structure, process, and actions (e.g., hazard identification, regional vulnerability assessment), as well as the overall network development of the participants [3]. Collaboration in catastrophic events is crucial in emergency management strategy because the collective efforts of various actors can enhance resource mobilization and offer timely and efficient assistance to damaged areas $[4,5]$.

Participation of nonprofit organizations (NPOs) is vital for emergency management because NPOs often work together with governments and can offer assistance and resources [6], and collaborative 
mechanisms among NPOs have a positive influence on regional disaster resilience [7]. Notably, the active involvement of various participants forms vertical action and horizontal collaboration [8]. Studies have mainly focused on the motivations and functions of NPO engagement in emergency management processes [9]. Some studies have explored the factors mobilizing voluntary actions and resources in the emergency management process and pre-disaster plan development for preventing potential risks $[10,11]$, whereas others have focused on the functions of NPOs in emergency service delivery $[12,13]$ and capacity building in collaborative emergency management $[1,5]$. However, the disaster services of NPOs and NPO strategies for network building and resource integration have not been comprehensively studied. Many local governments face challenges in integrating voluntary manpower, which influences the integration of regional disaster NPOs [14]. To counter this, local governments have attempted to develop collaborative mechanisms among NPOs before the occurrence of catastrophic events. This indicates why the proper engagement of NPOs at different stages of the emergency management process remains a major concern for scholars and practitioners; diligent emergency plans and initiatives with active NPO engagement can mitigate disaster losses, prevent future risks [15], and enhance emergency service delivery [16,17].

The experience of joining disaster relief efforts is valuable to public officials and practitioners, but current research investigating NPOs' experiences in disaster relief following extreme events is limited. This study examined the experiences of Taiwanese NPO collaboration in the disaster relief efforts for the 2008 Wenchuan Earthquake in China and 2009 Typhoon Morakot in Taiwan. To fill the current research gap regarding NPO disaster service alliances, this study explored the following three questions: (1) How did Taiwanese NPOs develop disaster service alliances or collaboration mechanisms for the Wenchuan Earthquake and Typhoon Morakot? (2) What types of disaster response and resource integration strategies did NPOs engage in for the two disasters? (3) What factors contribute to successful NPO collaborations in disaster relief work? To answer these questions, we employed semi-structured interviews and a questionnaire survey to ask NPO managers about the collaborative strategies and factors influencing long-term disaster service alliances during extreme events.

\section{Functions of NPOs in Emergency Management}

The emergency management process generally includes four stages: mitigation, preparedness, response, and recovery. Emergency plans and initiatives with active volunteers and NPO engagement can not only decrease disaster losses and the probability of potential risks $[16,18]$ but also offer service delivery to people in need $[12,15]$. The literature to date has provided insights into the two main functions of NPOs in the emergency management process: (1) as a catalyst of citizen participation in emergency management and (2) as enhancement of emergency management capacity for governments.

\subsection{Catalyst of Citizen Participation in Emergency Management}

In emergency management studies, deciding the emergency management capacity of governments is a political issue because it involves informing people and public officials about hazards and determining their willingness to engage in the emergency management process [19]. However, NPOs can strengthen relations between citizens and local governments and create opportunities for citizens to engage in establishing collaborative governance structures [10].

NPOs are considered a catalyst of citizen engagement in disaster preparedness because they complement the limited organizational capacity of local governments. Through involvement in the emergency management process, volunteers and citizens can contribute to society and present their concerns to public officials [11,20]. In some cases, grassroot NPOs play a main role in implementing citizen engagement initiatives, creating more opportunities for citizen involvement in community affairs, and assisting citizens in partnering with local governments [21].

One of the main functions of NPOs is to enhance public responses to emergency events and join disaster response exercises, and undertake preparedness activities to decrease possible damage to human life and property [22]. Based on the community-based disaster management approach, residents 
who volunteer in NPOs actively will participate in disaster response tasks and protect themselves from potential risks because of the built-in methods of citizen engagement in the emergency management process [23].

\subsection{Enhancing Emergency Management Capacity for Governments}

Facing ever-changing and dynamic environments, network participants in the emergency management process create complex systems of disaster response [24]. Public agencies dominate disaster responses; however, they possess limited capacities and organizational fragility, which means they cannot solely manage emergency situations $[25,26]$. The enhancement of NPO engagement is the chief factor in developing community resilience because community-based NPOs assist in the delivery of accurate information, disseminate emergency messages, and offer emergency services to local residents $[27,28]$. In addition, NPOs fulfill the shortfall in the service-delivery capacity of public organizations [2]. When public organizations face capacity decrement, focus is placed on the increasing demand for more public services from citizens and private organizations, the continuing wave of decentralized service delivery, and the government-NPO relationship.

An increase in the scope of disaster threats may encourage governments to involve more NPOs in the emergency response system, and NPOs have the civic responsibility and moral imperative to follow the guidelines and commands of governments [7,9]. Importantly, emergency volunteers are viewed as proper "average citizens." These "average citizens" not only relay information to emergency experts to provide them with a better understanding of local conditions but also offer assistance during catastrophic events $[29,30]$. These emergency volunteers, such as the volunteers of Red Cross, serve as primary respondents to emergency events, but are also participants in emergency preparedness, planning, response, and recovery [31].

\section{Main Types of Emergency NPOs in Taiwan}

Taiwan has three main local emergency NPOs: The Phoenix Volunteer Team, Women's Fire Prevention Promotion Team, and Volunteer Firefighter Unit. Based on their requirements and local situations, some cities or townships may have additional local emergency volunteer organizations. Because of the development of local emergency response approaches, almost every city or township in Taiwan has volunteer firefighter teams to assist local fire branches in responding to regional emergency events, such as fires, floods, earthquakes, and typhoons [7]. Other counties have similar provisions for formation of relative volunteer firefighter organizations. In the United States, for instance, the Community Emergency Response Team, made up of volunteers who are trained by professionals, responds to disasters and cleans up damage caused.

The Phoenix Volunteer Team in Taiwan mainly offers emergency medical services in coordination with local fire branches. Some cities or townships do not have a Phoenix Volunteer Team for various reasons, such as issues of citizen engagement, willingness of local fire branches, and volunteer management problems. In terms of their roles, the Volunteer Firefighter Unit and Phoenix Volunteer Team offer immediate assistance when regional disasters occur, whereas the Women's Fire Prevention Promotion Team focuses on the implementation of emergency preparedness plans. Before disaster occurrence, they join disaster response exercises and plan and deliver disaster response information to the public, particularly imparting emergency-related knowledge and approaches to potential disaster responses [25].

In addition to these three main NPOs for disaster reduction and response in Taiwan, numerous NPOs offer services during and after disasters. Since the 921 Earthquake in 1999, volunteer groups in Taiwan have proactively established several disaster service alliances. These included the National Civil Post-Disaster Recovery Alliance (117 members) for the 921 Earthquake, and the 88 Flooding Service Alliance (145 members) for 2009 Typhoon Morakot. Nationally well-known volunteer groups in Taiwan have provided various services in disaster areas, serving as catalysts in developing new regional community development associations and groups and assisting long-established groups in capacity 
building and organizational transformation. For example, the Tzu Chi Foundation, a Taiwanese international humanitarian and nongovernmental organization with more than 10 million members worldwide, works on medical aid, disaster relief, environmental sustainability, and social education. In disaster relief operations, the Tzu Chi Foundation provides post-disaster aid and develops long-term projects to rebuild and recover affected communities [2].

\section{Collaborative Governance in Catastrophic Events}

Governments are not the only authorities offering public services and dominating public affairs. National governments delegate their responsibilities to the private sector, NPOs, or other levels of government [32]. Policy implementation and service delivery may be conducted by the private sector or NPOs, and therefore public organizations seek partners willing to work together in the emergency management process $[33,34]$. Hence, developing partnerships and collaborations is advocated as the main approach through which to gather multiple actors or organizations together to solve problems [35].

Collaborative governance is consensus oriented and involves sharing, participation, cooperation, communication, and agreement based on compromises, trust, mutual understanding, and sharing of information and resources. Successful collaborative governance consists of a relationship among interrelated components, mainly active participation of stakeholders, network structure, institutional design, and leadership [36]. External and internal capacity, previous experience, and the degree of environmental uncertainty are major factors influencing NPOs' collaboration intention. However, the collaborative process is dynamic; public managers consider shared goals, individual commitment, mutual understanding of participants, and rules in the development process of collaboration. In addition, effective communication and positive mutual interaction matter when individual groups who have different experiences, values, and service orientations unite [37]. Facing environmental uncertainty, individuals must think of strategies to collaborate. People sharing information and resources can unite to create a collaborative platform that prevents resource waste and inefficiency. Collaborative platforms can regulate individual actions, which might benefit the outcome of collective activities [38].

Catastrophes lead to high uncertainty, and simultaneous demands for resources generate high risk and high cost to the participants in disaster management [39]. Scholars and professional organizations have urged collaborative governance in disaster events. Collaborative governance is viewed as a key emergency management mechanism by governments because such governance is expected to assist disaster responders in maximizing available capabilities and resources. However, without stakeholder participation in emergency preparedness, collaborative emergency management may fail to protect residents from potential risks and the negative effects of a disaster.

Collaborative emergency management emphasizes coordinated community disaster responses, which include past disaster experiences and the degree of coordination between disaster responses, networks, and organizational capacities, all of which are direct or indirect influences on public preparedness for emergencies [1]. Moreover, collaborative emergency management focuses on the operation of emergency management networks and expects that collaborative networks with effective resources usage will influence the behavior of NPOs participating in the emergency management process [30]. Notably, multiple participants are one of the main characteristics of collaborative emergency management, and NPO participation in the emergency process is valued for assisting emergency response [29].

Many local governments have used various emergency management systems for disaster mitigation, preparedness, response, and recovery. In some cases, local governments have learned to collaborate with other disaster event actors based on previous disaster experiences. Emergency management systems and disaster experiences leverage the capacity and resources of NPOs, which can provide immediate services, such as food, shelter, and medical aid, to the disaster area [40]. 
NPOs have multiple roles in relation to governments, namely complementary, supplementary, and adversarial roles [41]. In supplementary mode, volunteer groups fulfill a demand for public goods that governments are unable to fulfill. In complementary mode, volunteer groups may be regarded as partners of government to deliver public services through joint plans and program development. Adversarial mode emphasizes that NPOs trigger governments to adjust policies by acting as monitoring groups to ensure public services and goods are provided for those in need [7]. However, in some cases, NPOs compete with first responders and duplicate services that governments have offered [42,43]. Therefore, local governments have sought closer working relationships with NPOs in extreme events, especially in relief and recovery efforts, to integrate the limited resources available and maximize resource utility.

\section{Background for the Two Major Disasters and Participation}

A magnitude 8.0 earthquake with its epicenter in Wenchuan, Sichuan Province, China, occurred on May 12, 2008. As of September 2008, of the approximately 15 million people in affected areas, about 69,227 people were confirmed dead with 17,912 listed as missing and 143,367 seriously injured [44,45]. The China National Disaster Relief Commission first initiated a Level II Emergency Contingency Plan but soon upgraded it to a Level I. Then, China's Premier Wen Jiabao went to the affected areas $90 \mathrm{~min}$ after the earthquake to supervise rescue operations. On the same day, over 10 emergency relief and medical teams and about 50,000 troops and policemen were quickly dispatched to the impacted areas. Moreover, several foreign rescue or relief teams, including the Red Cross Society of Taiwan and Tzu Chi Foundation, joined the relief efforts. Through the Wenchuan Earthquake Taiwan Service Alliance, the Red Cross worked together with numerous NPOs from Taiwan to provide disaster services for victims $[2,14]$.

On 9 August 2009, Typhoon Morakot caused catastrophic damage in the southern part of Taiwan. The storm produced tremendous rainfall in a short period of time and resulted in enormous mudslides and severe floodings throughout southern Taiwan. This disaster, also called the 88 Flooding, left more than 680 people dead, with a total economic loss of approximately NT\$110 billion. One mudslide that buried Xiaolin Village in then Kaohsiung County was responsible for more than 400 deaths [46]. The storm was the worst typhoon to strike Taiwan in 50 years, but all levels of the government were apparently unprepared. In the wake of the disaster, local governments were also unable to effectively respond to the calamity. President Ma Ying-jeou faced severe criticism for his poor leadership and slow response to the disaster [47].

Numerous NPOs offered services during and after the occurrence of these disasters. Since the 921 Earthquake in 1999, Taiwanese NPOs have proactively established several disaster service alliances. These included the National Civil Post-Disaster Recovery Alliance for the 921 Earthquake, Wenchuan Earthquake Taiwan Service Alliance for the Wenchuan earthquake, and the 88 Flooding Service Alliance for Typhoon Morakot. Nationally well-known NPOs in Taiwan have provided various services in disaster areas, helping to develop new regional community development associations, and assisting long-established groups in capacity building and organizational transformation [2]. For example, the Red Cross Society of Taiwan and Tzu Chi Foundation were actively involved in disaster relief. On the basis of their relief work experience in Sichuan, the Red Cross Society of Taiwan established the 88 Flooding Service Alliance to coordinate recovery efforts by other NPOs following Typhoon Morakot. Thanks to this alliance, numerous local NPOs, such as religious organizations and community development associations, as well as national NPOs approached the affected areas and offered various services to those affected.

\section{Methodology}

This study used a questionnaire survey and semi-structured interview method to examine collaborative strategies during these two events. First, to discern the dynamics of the collaboration mechanism, the survey topics included three parts: (1) How did NPOs respond and engage in service 
offering following these two major disasters? (2) What are the disaster response strategies of NPOs? (3) What are the perceptions of NPO managers on the establishment of a standing disaster service alliance in the future? The survey samples were the member organizations of the 88 Flooding Service Alliance. A total of 155 surveys were distributed with 62 respondents for a response rate of $40 \%$. Responses were received by mail because some member organizations had left the alliance after the mission was completed. Descriptive analysis was employed to understand the data distribution of the NPO managers' opinions, and interview data were then collected to support the descriptive analysis results and provide more evidence for the findings. From Table 1, most of the respondents came from charity organizations, followed by education, culture, and mental health NPOs. Moreover, half were from local NPOs and half from nonlocal NPOs.

Semi-structured interviews were employed according to the collaborative governance theory. After seeking approval for interviews, 19 of the primary participants of the 88 Flooding Service Alliance were obtained. The criteria for sampling were whether they had experience in victim settlement and post-disaster recovery in addition to disaster service delivery. The following open-ended questions were asked: (1) Please describe the background of your organization. (2) What are the resource integration strategies that your organization has adopted for extreme disaster events? (3) Could you share your collaboration experiences with local governments and other organizations and indicate the pros and cons of the disaster service collaboration experience? (4) What are your views regarding the development and operation of standing and long-term disaster service alliances?

Table 1. Main Characteristics of the Survey Respondents.

\begin{tabular}{|c|c|c|c|}
\hline Organizational Mission & Local & Nonlocal & Total \\
\hline Education and Culture & 8 & 7 & $15(24.2 \%)$ \\
\hline Mental Health & 4 & 7 & $11(17.7 \%)$ \\
\hline Charity & 12 & 15 & $27(43.5 \%)$ \\
\hline Others & 7 & 2 & $9(14.5 \%)$ \\
\hline Total & 31 & 31 & $62(100 \%)$ \\
\hline Percentage & $50 \%$ & $50 \%$ & \\
\hline
\end{tabular}

Note: Others includes religious and information services.

The results in Table 2 show that 17 NPOs engaged in offering disaster services and 12 NPOs joined the Wenchuan Earthquake Taiwan Service Alliance. Most of the participating NPOs were nonlocal because the disaster relief operation was outside Taiwan. By contrast, 62 NPOs went to the damaged areas and offered various services after Typhoon Morakot. More than $80 \%$ of these NPOs participated in the 88 Flooding Service Alliance. Local organizations were more prevalent and were approximately equal in number with nonlocal NPOs.

Table 2. NPOs' Alliance Participation and Organization Types.

\begin{tabular}{cccc}
\hline Major Disasters & Offer Disaster Services & Join the Alliance & Types of Organization \\
\hline Wenchuan Earthquake & $17(27.4 \%)$ & $12(70.6 \%)$ & Local Org. $=3(21.4 \%)$ \\
& $\mathrm{N}=62$ & $\mathrm{~N}=17$ & Nonlocal Org. $=10(71.4 \%)$ \\
& & & Other $=1(7.1 \%)$ \\
\hline Typhoon Morakot & $62(100 \%)$ & $50(80.6 \%)$ & Local Org. $=31(50 \%)$ \\
& $\mathrm{N}=62$ & $\mathrm{~N}=57$ & Nonlocal Org. $=31(50 \%)$ \\
\hline
\end{tabular}

On the basis of the interviews, we determined eight main resource strategies: (1) Information sharing and exchange, which emphasizes mutual communicative activities. (2) Integration of service networks, which involves integrating the numerous service offerings from NPOs to form a service-provider connection. (3) Establishment of strategic alliances to form strong agreements among various NPOs. The NPOs pursue the objectives agreed by these organizations. (4) Project 
collaboration, which indicates partnering on projects for public service delivery with centralized communications and self-managing participants. (5) Advocacy of common concerns, which specifies that NPOs present their own perspectives to each other and determine common issues and objections to overcome possible disagreements. (6) Sharing of management functions, which means that, to maximize disaster relief, NPOs can be assigned duties, activities, and manpower based on emergency management requirements. (7) Contracting-out projects, which illustrates that NPOs set up service projects with contractors to deliver services during disasters. (8) Sharing of financial burden, which focuses on spending in terms of equipment and staffing. (9) Besides these eight, other areas included co-fundraising, co-purchasing goods and services, organizational merger, and cooperation.

\section{Findings and Discussion}

\subsection{Approaches to Developing Disaster Service Alliances}

Based on the analysis results, the main factors that Taiwanese NPOs used to develop the Wenchuan Earthquake Taiwan Service Alliance and 88 Flooding Service Alliance were determined.

\section{(1) Participatory Commitment of NPOs}

Taiwan NPOs were actively involved in disaster relief efforts for the Wenchuan Earthquake in China and Typhoon Morakot in southern Taiwan. Issue-based coalitions were observed to be distinct from well-developed, reliable teamwork in terms of durability, relationships and interaction among participants, and the views and attitudes of each entity [48]. Disasters pose a severe challenge for local people and regional development; therefore, NPOs must fully commit to disaster relief.

(2) Alliance Initiators and Key Network Actors' Involvement

The alliance initiator, with high capacity and past disaster relief experience, was crucial in the building of collaborative platforms. Both disaster relief alliances were organized by the Red Cross Society of Taiwan, who played a considerable role in coordination, communication, and fundraising. Because of its disaster relief experiences, the Red Cross Society of Taiwan functioned as a network-spanner in establishing the Wenchuan Earthquake Taiwan Service Alliance and 88 Flooding Service Alliance.

In the disaster relief process, the Red Cross Society of Taiwan provided leadership and coordinated the integrated services of NPOs. The services included temporary shelters, relief supplies, transportation pick-up services, demand assessments, condolence money to victims, face-to-face visits, and disaster recovery consultations [49]. Moreover, the key network actors' involvements expanded the collaborative networks. For example, the Red Cross Society of Taiwan and Tzu Chi Foundation have been actively involved in the disaster relief work nationwide. Both volunteer groups also provide emergency education, disaster relief, and assistance globally. Although not being the member of the disaster service alliances, the Tzu Chi Foundation worked independently on disaster relief and permanent housing for victims as well as delivered excellent volunteers and logistics after the Wenchuan Earthquake in China and Typhoon Morakot flooding in southern Taiwan.

\section{(3) Individual NPOs' Disaster Response Approaches}

The results in Table 3 show main NPOs' disaster response approaches. Joining a disaster relief alliance is a priority for NPOs reacting to disaster events. In the emergency collaborative management process, NPOs join groups to avoid risk or conflict. After disasters, joining an alliance for disaster relief services provides NPOs with more information about the status of affected areas, meaning they can better prepare to provide relief. Several cases have demonstrated that approaching affected areas without collaborating with other organizations can negatively affect emergency management [40].

NPOs contribute services in community disaster recovery and relief $[8,12]$. Affected areas require resources, and the most important thing for NPOs is to provide those areas and people in need with manpower and charitable assistance (e.g., mass feeding operations). 
All the interviewees opined that the main role of NPOs was ancillary to that of governmental disaster relief. Emergency relief and recovery are primarily the responsibility of government, although the role of NPOs has grown because of the positive value shown by NPO participation in the disaster relief process.

Relief supply delivery is critical and requires resource logistics and distribution. Some NPOs dispatched supply parcels to deliver food and supplies to those affected. Most NPOs were ready for logistics work and delivered relief supplies based on their standard operating procedures for disaster resource management. Such supplies included daily commodities, water, and food.

Some NPOs with disaster relief experience preferred to first evaluate the disaster affected areas to gauge what they could do and how they could work together with the local government, local organizations, and other external groups to reduce waiting times in the affected areas. These NPOs felt that each disaster zone is different, and therefore each requires evaluation to determine the scale of the damage and how best to help.

NPOs with limited internal resources and financial capacities would initiate fundraising events for donations so that they could provide more resources for the affected areas and purchase more goods for those in need. Online fundraising is a common route through which most such NPOs raised money because of time and cost concerns as well as donor preferences. In some cases, NPOs used social media, such as Facebook, to deliver donation information. However, often members of those NPOs donated money and actively contributed irrespective of whether they directly received donation information from NPOs.

Table 3. NPOs' Disaster Response Approaches.

\begin{tabular}{lc}
\hline \multicolumn{1}{c}{ Disaster Response Strategies } & N (\%) $\boldsymbol{n}=\mathbf{6 1}$ \\
\hline (1) Join the Alliance for disaster service offering & $44(72.1 \%)$ \\
(2) Assist in resource sharing and connection & $40(65.6 \%)$ \\
(3) Ancillary to governments' disaster relief & $24(39.3 \%)$ \\
(4) Deliver relief supplies & $22(35.5 \%)$ \\
(5) Go to disaster areas immediately & $21(34.4 \%)$ \\
(6) Initiate fundraising events & $20(32.8 \%)$ \\
\hline
\end{tabular}

\subsection{Resource Integration Strategies of NPOs}

The results in Table 4 show main emergency resource integration strategies of NPOs. Information sharing and exchange can enhance mutual understanding and interaction among the actors in a disaster relief process, which can help manage resource inventory through mutual communication. Moreover, collaborative teamwork forms an integrated service network, which emphasizes linking each NPO's resources to the areas and people most in need [50]. A new form of relationship, such as an alliance, can enhance collaborative governance in the emergency management process and, in turn, increase collaboration among similar and proximal organizations [10]. Furthermore, overlapping of services and goods provided by NPOs is reduced because they can now mutually consider the most efficient use of resources.

Establishing a strategic alliance for managing information sharing, exchange, and feedback can benefit cross-sector collaboration. Issues regarding resource competition and cooperation remain between national and local organizations. Based on the relief and recovery experience of the 921 Earthquake, there is an increased need for collaboration mechanisms to handle resource competition and cooperation problem between national and local organizations [51].

Some NPOs prefer to have service projects with others in addition to their core offerings. Several service project teamwork types exist in different stages of the disaster process. During the placement and shelter stage, national NPOs, such as the Jieh-Huey Social Welfare and Charity Foundation, Child Welfare League Foundation, and Taiwan Fund for Children and Families, collaborated to move victims from temporary shelters into military barracks. In the post-disaster 
recovery stage, NPOs helped maintain psychological well-being as they rebuilt victims' lives through a series of services. Such services typically included physical activity counseling, schooling, employment assistance, social welfare, and daily life support. Additionally, the Red Cross Society of Taiwan, Tzu Chi Foundation, and World Vision Taiwan provided permanent housing for victims, which was the first instance of NPOs providing permanent housing after a catastrophe in Taiwan.

Table 4. Resource Integration Strategies of NPOs.

\begin{tabular}{lc}
\hline \multicolumn{1}{c}{ Resource Integration Strategies (Orderly) } & Times (\%) $\boldsymbol{n}=\mathbf{6 0}$ \\
\hline (1) Information sharing and exchange & $45(75 \%)$ \\
(2) Integration of service network & $36(60 \%)$ \\
(3) Establishment of strategic alliance & $26(43.3 \%)$ \\
(4) Project Collaboration & $25(41.7 \%)$ \\
(5) Advocacy of common concerns & $24(40 \%)$ \\
(6) Sharing of management functions & $12(20 \%)$ \\
(7) Contracting-out project & $4(6.7 \%)$ \\
(8) Sharing of finance burden & $4(6.7 \%)$ \\
(9) Others & $6(10 \%)$ \\
\hline Others include
\end{tabular}

\subsection{Key Factors for a Successful Standing Disaster Service Alliance}

Preexisting collaboration networks provide considerable benefits in disaster relief [52]. The interview data in the present study indicated that the alliance initiator functions as the catalyst in the growth and development of an alliance. Importantly, developing disaster service alliances decreases the collaborative cost of disaster first responders and maximizes available capability and resources. Capitalizing on relief work experience from the Wenchuan Earthquake, the Red Cross Society of Taiwan established the 88 Flooding Service Alliance to coordinate the recovery efforts of more than 70 NPOs in the wake of Typhoon Morakot. The network proved successful. Notably, the findings of this study indicate that resource competition and lack of cooperation between nonlocal and local organizations are the main concerns for NPOs participating in disaster relief. Based on the experiences from the Wenchuan Earthquake and Typhoon Morakot, collaborative mechanisms are strongly recommended for NPOs participating in relief operations. Regarding the need for a standing disaster service alliance in the future, approximately $96 \%$ of respondents strongly agreed that it would be a good idea (Table 5).

Table 5. Need for Standing Disaster Service Alliance.

\begin{tabular}{cccc}
\hline Very High & High & Low & Very Low \\
\hline $31(60.8 \%)$ & $18(35.3 \%)$ & $2(3.9 \%)$ & $0(0 \%)$ \\
\hline
\end{tabular}

Most of the NPO managers suggested that NPOs' engagement in the disaster alliances was crucial for disaster relief efforts in both catastrophic events. The two alliances proved effective mechanisms of collaboration in the disaster relief work. However, for a successful standing disaster service to have long-term development potential, several factors must be considered. The results in Table 6 show key factors for a successful standing disaster service alliance.

First, a self-designed rule consisting of NPOs based on mutual communication and interaction. NPOs that have broad overlaps in service offerings are more likely to form collaborations [53]. In the present study, all the NPOs were disaster-services NPOs, which meant that their service offerings had high degrees of overlap. To enhance the use and growth of efficient resource and service networks, each NPO must assist in resource sharing and connection.

Disaster relief resources should be complementary and shareable, and the connection among participating NPOs should be based on mutual trust. Collaboration is a managerial mechanism, which 
contributes to building accountability and trust in a disaster service alliance [54]. Moreover, trust among collaborators is crucial because trust decreases transaction costs and interaction uncertainty in the collaborative process [55]. Because collaboration involves multiple stakeholders rather than a single public organization, it encourages public organizations to be accountable for accomplishing shared goals and to have a common vision. Common vision among collaborative participants can form strong agreement with less cost to communication. During the collaborative process, multiple participants must coordinate and integrate service delivery and resolve collective action problems.

Leadership is critical in a disaster service alliance. The Red Cross Society of Taiwan functioned as a network-spanner in establishing the Wenchuan Earthquake Taiwan Service Alliance and 88 Flooding Service Alliance and developing collaborative efforts for the two major catastrophes outlined in this study. The Red Cross played a considerable leadership role in coordinating, communicating, fundraising, and resource sharing. Additionally, the leaders of several nationally known NPOs in Taiwan, such as the Child Welfare League Foundation, the League of Welfare Organizations for the Disabled, Federation for the Welfare of the Elderly, and the Garden of Hope Foundation, managed internal resources and committed collective actions with others. Those NPOs acted as catalysts in local community development associations and also assisted long-established groups in capacity building and organizational transformation.

Financial sources influenced individual NPOs to join the standing disaster service alliance. Approximately 18 of the 62 NPO respondents (33.3\%) suggested that the government and NPOs contribute equal funds to disaster relief. Only three large NPOs with strong capacity could self-finance, and most of the NPOs relied on donations and government support. Borrowing and lending complementary resources enhanced NPOs collaborative willingness because some resource types were lacking, which meant that NPOs would seek external resources and offer complementary resources in return.

Finally, competition exists among NPOs for media exposure and service receivers' satisfaction, but collaboration is an efficient approach to ensure NPOs move beyond competition and sufficiently increase resource use [56]. In some cases, NPOs have less information about the methods to deliver disaster services to those in need and consequently focus efforts in the wrong areas, resulting in inefficient outcomes. However, collaboration can help NPOs offer services strategically [57].

In summary, the promise of collaboration among NPOs in the form of a disaster relief alliance promotes and reinforces ongoing disaster relief efforts by building capacity and promoting responsibility and strategic thinking, rather than competition. NPO engagement in disaster relief and recovery processes has numerous advantages, including experience in disaster rescue and assistance, decentralized regional networks, and feasible and flat organizations. However, some NPO managers in this study asserted that NPOs participating in disaster services encountered several challenges, including varying collaborative methods among NPOs, goal discrepancy, different organizational cultures, role dilemmas, and conflicts between national and local organizations.

Table 6. Key Factors for a Successful Standing Disaster Service Alliance.

\begin{tabular}{lc}
\hline \multicolumn{1}{c}{ Key Factors } & Time (\%) \\
\hline Social network connection & $48(78.7 \%)$ \\
Resource complementarity & $46(75.4 \%)$ \\
Resource sharing & $41(67.2 \%)$ \\
Mutual trust & $36(59 \%)$ \\
Common organizational vision & $34(54.7 \%)$ \\
Partnership & $32(52.5 \%)$ \\
Significant support from governments & $27(44.3 \%)$ \\
Self-financing & $24(39.3 \%)$ \\
Organization leadership & $19(31.1 \%)$ \\
Sufficient resources & $16(26.2 \%)$ \\
\hline
\end{tabular}




\section{Conclusions}

This study examined the role of NPOs in the emergency management process, the causes and effects of collaborative governance, and the experiences of Taiwan NPOs' collaboration in disaster relief efforts in the Wenchuan Earthquake in China and Typhoon Morakot in Taiwan. This study has high significance in the following aspects: first, the study offers lessons about Taiwan NPOs' collaboration in disaster relief efforts. One of the findings is that NPOs' participation in disaster relief is becoming increasingly vital, but competition and collaboration may exist among participating NPOs. And a disaster service alliance can assist disaster relief collaboration.

Second, the study identified the disaster resource integration strategies of NPOs. Major strategies for the resource integration of participating NPOs are information sharing and exchange and integration of service networks. Notably, NPO managers emphasized that a successful standing disaster service alliance would mainly require the following factors: social network connection, complementary resources, resource sharing, and mutual trust. Finally, respondents in this study expressed positive opinions toward the establishment of standing disaster service alliances, believing that such alliances are highly feasible; moreover, most expressed a willingness to join such an alliance in the future. However, such an alliance significantly relies on financial support, which probably reflects why Taiwan NPOs wish to maintain autonomy and flexibility in disaster relief efforts.

The study provides evidence to public officials and NPO managers to assess the factors influencing long-term and flexible disaster service alliances. However, inadequate survey data in this study of some NPO organizational characteristics may limit conducting further analyses. Another limitation is that the development of collaboration appears to be linked to the external environment. However, this observation must be verified formally. Furthermore, questions remain as to how influential the initiator in a network might be in the development of collaboration. These findings suggest that the nature of informational and resource sharing strategies is a vital determinant of collaboration in disaster relief. Future research could examine whether organizational and institutional factors contribute to collaboration. In addition, future research can examine empirically the factors of successful long-term standing disaster service alliances in order to predict the likelihood of collaboration in extreme events or to predict specific collaborative strategies in the emergency management process.

Author Contributions: These authors contributed equally to this work. All authors read and approved the final manuscript.

Funding: This research was mainly funded by the Relieve Disaster Foundation, Taiwan.

Acknowledgments: The survey and interviews were conducted with the support of another research project, "The Resource Integration Strategies for NPOs in Coping with Catastrophic Disasters. The authors are grateful to Yan Feng (project leader) and other team members for their assistance in questionnaire design and implementation, as well as interviews.

Conflicts of Interest: The authors declare no conflict of interest.

\section{References}

1. Kapucu, N. Collaborative Emergency Management: Better Community Organising, Better Public Preparedness and Response. Disasters 2008, 32, 239-262. [CrossRef] [PubMed]

2. Lai, A.Y.H. Towards a Collaborative Cross-border Disaster Management: A Comparative Analysis of Voluntary Organizations in Taiwan and Singapore. J. Comp. Policy Anal. Res. Pract. 2012, 14, $217-233$. [CrossRef]

3. Jensen, J.; Carr, J. Predisaster integration of community emergency response teams. J. Emerg. Manag. 2015, 13, 25-35. [CrossRef] [PubMed]

4. Koliba, C.J.; Mills, R.M.; Zia, A. Accountability in Governance Networks: An assessment of Public, Private, and Nonprofit Emergency Management Practices Following Hurricane Katrina. Public Adm. Rev. 2011, 71, 210-220. [CrossRef] 
5. Oh, N.; Okada, A.; Comfort, L.K. Building Collaborative Emergency Management Systems in Northeast Asia: A Comparative Analysis of the Roles of International Agencies. J. Comp. Policy Anal. Res. Pract. 2014, 16, 94-111. [CrossRef]

6. Wu, W.N.; Chang, S.M.; Collins, B.K. Mobilizing Voluntary Organizations in Taiwanese Emergency Response: Citizen Engagement and Local Fire Branch Heads. J. Contemp. East. Asia 2015, 14, 45-55. [CrossRef]

7. Jenkins, P.; Lambeth, T.; Mosby, K.; Van Brown, B. Local nonprofit organizations in a post-Katrina landscape: Help in a context of recovery. Am. Behav. Sci. 2015, 59, 1263-1277. [CrossRef]

8. Eller, W.S.; Gerber, B.J.; Robinson, S.E. Nonprofit Organizations and Community Disaster Recovery: Assessing the Value and Impact of Intersector Collaboration. Nat. Hazards Rev. 2017, 19, 05017007. [CrossRef]

9. Smith, S.L. Coping with disaster: Lessons learned from Executive Directors of nonprofit organizations (NPOs) in New Orleans following Hurricane Katrina. Adm. Soc. Work 2012, 36, 359-389. [CrossRef]

10. Simo, G.; Bies, A.L. The Role of Nonprofits in Disaster Response: An Expanded Model of Cross-sector Collaboration. Public Adm. Rev. 2007, 67, 125-142. [CrossRef]

11. Brudney, J.L.; Gazley, B. Planning to be Prepared: An Empirical Examination of The Role of Voluntary Organizations in County Government emergency planning. Public Perform. Manag. Rev. 2009, 32, 372-399. [CrossRef]

12. Arlikatti, S.; Bezboruah, K.; Long, L. Role of Voluntary Sector Organizations in Posttsunami Relief: Compensatory or Complementary? Soc. Dev. Issues 2012, 34, 64-80.

13. Kapucu, N. Non-profit response to catastrophic disasters. Disaster Prev. Manag. An Int. J. 2007, 16, 551-561. [CrossRef]

14. Carr, J.; Jensen, J. Explaining the pre-disaster integration of Community Emergency Response Teams (CERTs). Nat. Hazards 2015, 77, 1551-1571. [CrossRef]

15. Rotolo, T.; Berg, J.A. In Times of Need: An Examination of Emergency Preparedness and Disaster Relief Service Volunteers. Nonprofit Volunt. Sect. Q. 2011, 40, 740-750. [CrossRef]

16. Stevens, M.R.; Berke, P.R.; Song, Y. Creating Disaster-resilient Communities: Evaluating the Promise and Performance of New Urbanism. Landsc. Urban Plan. 2010, 94, 105-115. [CrossRef]

17. Manandhar, R.; McEntire, D.A. Disasters, Development, and Resilience: Exploring the Need for Comprehensive Vulnerability Management. In Disaster and Development; Springer: Cham, Switzerland, 2014; pp. 19-37.

18. Nelson, A.C.; French, S.P. Plan Quality and Mitigating Damage from Natural Disasters: A Case Study of the Northridge Earthquake with Planning Policy Considerations. J. Am. Plan. Assoc. 2002, 68, 194-207. [CrossRef]

19. Waugh, W.L., Jr. Assessing quality in disaster management. In Performance and Quality Measurement in Government; Chatelaine Press: Virginia, VA, USA, 1999; pp. 65-82.

20. Boris, E.T.; Steuerle, C.E. (Eds.) Nonprofits \& Government: Collaboration \& Conflict; The Urban Insitute: Washington, DC, USA, 2006.

21. Foster-Fishman, P.G.; Collins, C.; Pierce, S.J. An Investigation of the Dynamic Processes Promoting Citizen Participation. Am. J. Commun. Psychol. 2013, 51, 492-509. [CrossRef] [PubMed]

22. Quinn, S.C. Crisis and Emergency Risk Communication in a Pandemic: A Model for Building Capacity and Resilience of Minority Communities. Health Promot. Pract. 2008, 9 (Suppl. 4), 18S-25S. [CrossRef] [PubMed]

23. Luna, E.M. Disaster Mitigation and Preparedness: The Case of NGOs in the Philippines. Disasters 2001, 25, 216-226. [CrossRef] [PubMed]

24. Comfort, L.K.; Sungu, Y.; Johnson, D.; Dunn, M. Complex Systems in crisis: Anticipation and Resilience in Dynamic Environments. J. Conting. Crisis Manag. 2001, 9, 144-158. [CrossRef]

25. Wu, W.N.; Chang, K.; Tso, Y.E. If Only We Knew What We Know: Factors for Mobilizing Citizen Participation in Community-based Emergency Preparedness. Chin. Public Adm. Rev. 2016, 7, 77-109.

26. Scolobig, A.; Pellizzoni, L.; Bianchizza, C. Public Participation and Trade-Offs in Flood Risk Mitigation: Evidence from Two Case Studies in the Alps. Nat. Cult. 2016, 11, 93-118. [CrossRef]

27. Rumbach, A.; Makarewicz, C.; Németh, J. The Importance of Place in Early Disaster Recovery: A Case Study of the 2013 Colorado Floods. J. Environ. Plan. Manag. 2016, 59, 2045-2063. [CrossRef]

28. Cretney, R.M. Local Responses to Disaster: The Value of Community Led Post Disaster Response Action in a Resilience Framework. Disaster Prev. Manag. 2016, 25, 27-40. [CrossRef] 
29. Pearce, L. The Value of Public Participation during a Hazard, Impact, Risk and Vulnerability (HIRV) Analysis. In Mitigation of Natural Hazards and Disasters: International Perspectives; Springer: Berlin, Germany, 2005; pp. 79-109.

30. McLennan, J.; Birch, A. A potential Crisis in Wildfire Emergency Response Capability? Australia's volunteer firefighters. Glob. Environ. Chang. Part B Environ. Hazards 2005, 6, 101-107. [CrossRef]

31. Kapucu, N.; Garayev, V. Collaborative Decision-making in Emergency and Disaster Management. Int. J. Public Adm. 2011, 34, 366-375. [CrossRef]

32. Levi-Faur, D. From "Big Government" to "Big Governance". In The Oxford Handbook of Governance; OUP Oxford: Oxford, UK, 2012; pp. 3-18.

33. Provan, K.G.; Kenis, P. Modes of Network Governance: Structure, Management, and Effectiveness. J. Public Adm. Res. Theory 2008, 18, 229-252. [CrossRef]

34. Comfort, L.K. Inter-Organizational Design for Disaster Management: Cognition, Communication, Coordination and Control. J. Seismol. Earthq. Eng. 2007, 9, 61-71.

35. Ronan, K. Solving Wicked Problems Linked to Disasters, Risk and Uncertainty-Children are Truly Our Future. Aust. J. Emerg. Manag. 2014, 29, 8-9.

36. Ansell, C.; Gash, A. Collaborative governance in theory and practice. J. Public Adm. Res. Theory 2008, 18, 543-571. [CrossRef]

37. Emerson, K.; Nabatchi, T.; Balogh, S. An integrative framework for collaborative governance. J. Public Adm. Res. Theory 2012, 22, 1-29. [CrossRef]

38. Ansell, C.; Gash, A. Collaborative platforms as a governance strategy. J. Public Adm. Res. Theory 2017, 28, 16-32. [CrossRef]

39. Kim, J.W.; Jung, K. Does Voluntary Organizations' Preparedness Matter in Enhancing Emergency Management of County Governments? Lex Localis 2016, 14, 1-17. [CrossRef]

40. Haddow, G.D.; Bullock, J.A.; Coppola, D.P. Introduction to Emergency Management; Butterworth-Heinemann Homeland Security Series; Elsevier Science Limited: Amsterdam, The Netherlands, 2008.

41. Young, D.R. Complementary, Supplementary, or Adversarial? Nonprofit-Government Relations. Nonprofits and Government: Collaboration and Conflict; The Urban Insitute: Washington, DC, USA, 2006; pp. 37-80.

42. Gazley, B.; Brudney, J.L. The purpose (and perils) of government-nonprofit partnership. Nonprofit Volunt. Sect. Q. 2007, 36, 389-415. [CrossRef]

43. Robinson, S.; Murphy, H.; Bies, A. Structured to partner: School district collaboration with nonprofit organizations in disaster response. Risk Hazards Crisis Public Policy 2014, 5, 77-95. [CrossRef]

44. Jung, K.; Andrew, S.A.; Wu, W.N. Illuminating the in-house provision of emergency services: A test of organizational capacity hypotheses. Int. Rev. Public Adm. 2014, 19, 238-251. [CrossRef]

45. Wang, Z. A Preliminary Report on the Great Wenchuan Earthquake. Earthq. Eng. Eng. Vib. 2008, 7, $225-234$. [CrossRef]

46. Chen, Y.; Booth, D.C. The Wenchuan Earthquake of 2008: Anatomy of A Disaster; Springer Science and Business Media: Berlin, Germany, 2011.

47. Lai, A.Y.H. Organizational collaborative capacities in disaster management: Evidence from the Taiwan red cross organization. Asian J. Soc. Sci. 2011, 39, 446-468.

48. Chanson, H. The impact of Typhoon Morakot on the southern Taiwan coast. Shore Beach 2010, $78,33-37$.

49. Li, H.C.; Hsieh, L.S.; Chen, L.C.; Lin, L.Y.; Li, W.S. Disaster investigation and analysis of Typhoon Morakot. J. Chin. Inst. Eng. 2014, 37, 558-569. [CrossRef]

50. Burns, P.; Thomas, M.O. The failure of the nonregime: How Katrina exposed New Orleans as a regimeless city. Urban Aff. Rev. 2006, 41, 517-527. [CrossRef]

51. Chen, C.Y.; Lee, W.C. Damages to School Infrastructure and Development to Disaster Prevention Education Strategy after Typhoon Morakot in Taiwan. Disaster Prev. Manag. Int. J. 2012, 21, 541-555. [CrossRef]

52. Waugh Jr, W.L.; Sylves, R.T. Organizing the war on terrorism. Public Adm. Rev. 2002, 62, 145-153. [CrossRef]

53. Yang, Y. The 9/21 Earthquake in Taiwan: A Local Government Disaster Rescue System. Disasters 2010, 34, 112-136. [CrossRef] [PubMed]

54. Mattox, K.L. Hurricanes Katrina and Rita: Role of individuals and collaborative networks in mobilizing/coordinating societal and professional resources for major disasters. Crit. Care 2005, 10, 205. [CrossRef] [PubMed] 
55. Guo, C.; Acar, M. Understanding collaboration among nonprofit organizations: Combining resource dependency, institutional, and network perspectives. Nonprofit Volunt. Sect. Quarterly 2005, 34, 340-361. [CrossRef]

56. Stern, M.J.; Coleman, K.J. The Multidimensionality of Trust: Applications in Collaborative Natural Resource Management. Soc. Nat. Resour. 2015, 28, 117-132. [CrossRef]

57. Almoradie, A.; Cortes, V.J.; Jonoski, A. Web-based Stakeholder Collaboration in Flood Risk Management. J. Flood Risk Manag. 2015, 8, 19-38. [CrossRef]

(C) 2018 by the authors. Licensee MDPI, Basel, Switzerland. This article is an open access article distributed under the terms and conditions of the Creative Commons Attribution (CC BY) license (http:/ / creativecommons.org/licenses/by/4.0/). 